\title{
The hypothetical degradation trajectory in 'Overgrazing leads to soil cracking that later triggers the severe degradation of alpine meadows on the Tibetan Plateau' was not precisely right
}

\author{
Wenjing $\operatorname{Li}^{1}$ \\ ${ }^{1}$ Northwest Institute of Plateau Biology Chinese Academy of Sciences
}

October 16, 2020

\begin{abstract}
During reading the paper recently (Niu et al., 2019), I found that the hypothetical degradation trajectory was not of precisely validity. According to their data, they hypothesized a degradation trajectory of an alpine rangeland based on the cracking phenomenon induced by overgrazing.
\end{abstract}

The hypothetical degradation trajectory in 'Overgrazing leads to soil cracking that later triggers the severe degradation of alpine meadows on the Tibetan Plateau' was not precisely right

Wenjing $\mathrm{Li}^{1,2}$

${ }^{1}$ CAS Key Laboratory of Adaptation and Evolution of Plateau Biota, Northwest Institute of Plateau Biology, Chinese Academy of Sciences, Xining, Qinghai 810008, PR China

${ }^{2}$ Scientific Research and Popularization base of Qinghai-Tibet Plateau Biology, Qinghai Provincial Key Laboratory of Animal Ecological Genomics, Xining, Qinghai 810008, PR China

Correspondence

Li, CAS Key Laboratory of Adaptation and Evolution of Plateau Biota, Northwest Institute of Plateau Biology, Chinese Academy of Sciences, Xining, Qinghai 810008, PR China. E-mail address: lwenjing125@126.com

Dear Editor:

During reading the paper recently (Niu et al., 2019), I found that the hypothetical degradation trajectory was not of precisely validity. According to their data, they hypothesized a degradation trajectory of an alpine rangeland based on the cracking phenomenon induced by overgrazing. The first three stages and the last two were isolated in their hypothesis, and can be found in the figure legend in Figure 9 of their paper (Niu et al., 2019). The main result of this paper is that cracks were found in grassland under the conditions of overgrazing (Niu et al., 2019). The cracks became larger in cold season, became smaller in the plant growth season, and were a process of circulation of bigger and smaller (Niu et al., 2019). And if it just so, there was not a lot of bare patches in the grassland. But in the last two stages of their hypothesis, they put the figures of the habitat of the plateau pika (Ochotona curzoniae) with bare patches of different area. There was no plateau pika in their study site (Niu et al., 2019), and the overgrazing and disturbance of plateau pika were two independent factors, so they can not get the conclusion of the crack induced by overgrazing later triggers the severe degradation of alpine meadows on the Tibetan Plateau. 
Digging for food behavior of plateau pika was ignored by the former researches, and was not published in any journal before, and now is available in a preprint paper of Researchgate ( $\mathrm{Li}$ et al., 2020). The pika used its two forelegs together when digging on the ground, and pits of different size was left both on the primary grassland and former bare grounds ( $\mathrm{Li}$ et al., 2020). Ignored digging of plateau pika is the primary reason for the occurrence and enlargement of bare patches in alpine meadow ecosystem. And the occurrence and enlargement of bare patches by digging of plateau pika is an irreversible progress, and is different with the cracking become smaller in plant growth season of this study.

The soft layer soil with low water content on the surface of alpine meadow was the precondition of digging for food behavior of plateau pika in the long period of cold season. Diggings were more than $40 \%$ of the entire observation time in the cold season( $\mathrm{Li}$ et al., 2020). Soil with low water content on the surface of alpine meadow is the reason why the cracks became large in the cold season (Niu et al., 2019). After the soil cracking, the surface area increased, and the soil water content in this surface soil declined, and the crack became large. In the warm season, the soil water content increased, and the crack became small.

Although overgrazing and digging of plateau pikas are related to each other in alpine meadows, but affect the ecological progresses in different ways, so it is more necessary to carry out relatively independent research. The degradation of alpine meadows is a complex process in which different factors act in different ways and with different intensities. It is not appropriate to try to have a general theory about the grassland degradation in alpine meadow ecosystem.

This study (Niu et al., 2019) and our study (Li et al., 2020) focus on the ecological processes in long-term cold season of alpine meadow ecosystem, which is being the most under-researched period. The greater significance of this two study is to attract more attention to the window period (cold season) in the Tibetan Plateau and other areas.

Yours Li Wenjing

CAS Key Laboratory of Adaptation and Evolution of Plateau Biota, Northwest Institute of Plateau Biology, Chinese Academy of Sciences, Xining, Qinghai 810008, PR China

\section{ACKNOWLEDGMENTS}

This paper was financially supported by the Applied Basic Research Programs of Qinghai Province (2017ZJ-714), and CAS "Light of West China" Program.

\section{REFERENCES}

Niu Y., Zhu H., Yang S., Ma S., Zhou J., Chu B., Hua R. \& Hua L. (2019) Overgrazing leads to soil cracking that later triggers the severe degradation of alpine meadows on the Tibetan Plateau. Land Degradation \& Development, 30, 1243-1257 . https://doi.org/10.1002/ldr.3312 Li W.J., Zhang H., Wang Y.S., Hu YP (2020) Ignored digging of plateau pika is the primary reason for the occurrence and enlargement of bare patches in alpine meadow ecosystem. DOI:10.13140/RG.2.2.32428.28809 Preprint in Researchgate: https://www.researchgate.net/publication/344576622 